\title{
KINETIC STUDIES OF THE UNSATURATED ACIDS, OXIDISED BY PYRIDINIUMDICHROMATE: A MECHANISTIC APPROACH
}

\author{
Varsha Bishnoi, Om Prakash ${ }^{\bowtie}$ and Pradeep K. Sharma \\ Chemical Kinetics Laboratory, Department of Chemistry, J.N.V. University, Jodhpur,India \\ ${ }^{\square}$ Corresponding Author: drpkvs27@yahoo.com
}

\begin{abstract}
Studies on the oxidation of four unsaturated acids by pyridiniumdichromate (PDC) in dimethylsulphoxide (DMSO) lead to form the product epoxide. The reaction is found to be of first-order w. r. t. PDC and an M-M type (fractional order) kinetics are observed w.r.t. acids. Reactions are performed in a non-aqueous medium, the acid effect is studied by adding para toluene sulfonic acid. The reaction shows catalysis on the addition of an acid. The acid effect is shown through the reaction $k_{\text {obs }}=\mathrm{a}+\mathrm{b}\left[\mathrm{H}^{+}\right]$. Oxidation is studied in 19 organic solvent mediums, the effect of solvents experiments with the model of Kamlet's and Swain's multi-parametric equation. Cation solvating effects show the importance of finding out the suitable mechanism with three centered transition state is the taking part in the reaction process.
\end{abstract}

Keywords: Dichromate, kinetic study, mechanistic aspect, USA.

RASĀYAN J. Chem., Vol. 14, No.4, 2021

\section{INTRODUCTION}

In synthetic chemistry, oxidation studies of organic functions in non-aqueous media is a very selective process. A large variety of chromium compounds have already been used for the purpose are reported ${ }^{1-4}$ in literature. Pyridinumdichromate (PDC) has also been used for the oxidation of alcoholic compounds to carbonyl compounds 5 . Our group at Jodhpur has always been in search of these compounds for this purpose and various studies are emanated from our laboratory ${ }^{7-10}$. Oxidation studies of double bond compounds, alkenes by $\mathrm{CrO}_{2} \mathrm{Cl}_{2}$ and $\mathrm{HCrO}_{4}$ acid have been given much awareness ${ }^{11-12}$. Therefore, we have undertaken the studies of these four unsaturated acids by dichromate in non-aqueous media of dimethyl sulfoxide. The double bond acids used are fumaric FA, maleic MA, crotonic CrA and cinnamic acids $\mathrm{CiA}$ to be oxidized by PDC. We propose here a suitable mechanism and the reducing species taking part in the process.

\section{Material and Method}

\section{EXPERIMENTAL}

All the acids are available in the market and are taken into use as received. Oxidant was synthesized by the method available in the literature. ${ }^{5}$ Its purity was checked by the usual method of iodometry. Purification of all other compounds is done by the usual methods. ${ }^{13}$ Para toluene sulfonic acid is used for the hydrogen ion effect.

\section{Investigation of Products}

To ascertain the formation of the final product is done kinetically with 1: 10 ratio of reductant over oxidant. Characteristic experiments are undertaken with 0.2 moles of reductants (acid) and 1.58 grams / 0.01 mols of oxidant (dichromate) dissolving in a hundred milliliter of DMSO and kept for about twelve hours to be sure that reaction is complete. After this, the mixture is reacted with an excess $(250 \mathrm{~mL}) \mathrm{of}$ 2,4-DNP (Hydrazine) in hydrochloric acid and left for more than $12 \mathrm{hrs}$ in a freezing device, a precipitate 
RASĀYAN J. Chem.

Vol. 14 | No. 4 |2478-2485| October- December | 2021

of 2,4-DNP (Hydrazone) is so obtained is filtered off and dried also. Before its weighing, recrystallization is done with ethyl alcohol. The recovery of 2-DNPs, before and after re-crystallization is 2.58 gram and 2.53 grams $88 \%$ and $84 \%$ correspondingly. The DNP so obtained is exactly similar to DNP of Products and reactants in that order. The oxidation number obtained by iodometry is $3.95 \pm 0.10$.

\section{Kinetic Measurements}

Conditions of the pseudo-first-order are maintained by having an excess of acid on PDC. The medium is dimethyl sulfoxide. All the reactions are done under a temperature maintained constantly. Reactions are monitored on a spectrophotometer by recording the OD in descending order [PDC] at lambda max 361 nanometer to three half-life periods of time. The data for $\mathrm{k}-\mathrm{Obs}$ is estimated by the expression $\mathrm{k}_{2}=\mathrm{k}_{\mathrm{Obs}} /$ [Acid]. Reactions other than the acid effect are done without any acid.

\section{RESULTS AND DISCUSSION}

We have collected the results for all the reactants and found that they are almost similar; therefore, only some sample data is presented here:

\section{Stoichiometric Determinations}

Analysis of products so obtained confirms the presence of $\mathrm{CrA}$, CiA, MA / FA acid are $\mathrm{CH}_{3} \mathrm{COCH}_{3}$, $\mathrm{CH}_{3} \mathrm{COC}_{6} \mathrm{H}_{5}$ and $\mathrm{C}_{3} \mathrm{H}_{3} \mathrm{O}_{4}$ (Pyruvic acid) correspondingly. The reaction given below shows that these products are formed from rearrangements and decaboxylations of epoxides.

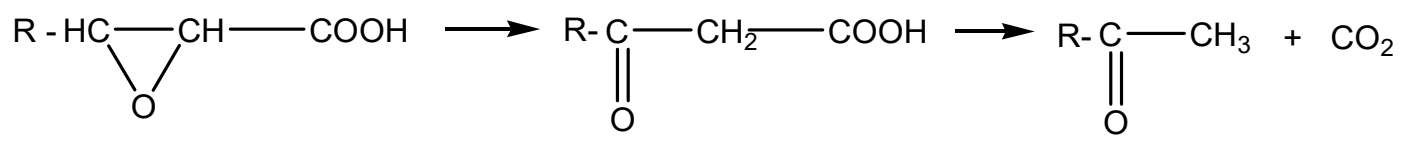

$(\mathrm{R}=\mathrm{Ph}, \mathrm{Me}$ or $\mathrm{CooH})$

It's a well-known fact that epoxides rearrange to the corresponding ketones ${ }^{14}$. $\beta$ - Keto-acids decarboxylation takes place very easily in acid solutions ${ }^{15}$. on the basis of this fact, the oxidations of these acids are represented as the below:

$2 \mathrm{R}-\mathrm{HC}=\mathrm{CH}-\mathrm{COOH}+\mathrm{Cr}_{2} \mathrm{O}_{7}^{-2}+10 \mathrm{H}^{+} \longrightarrow$

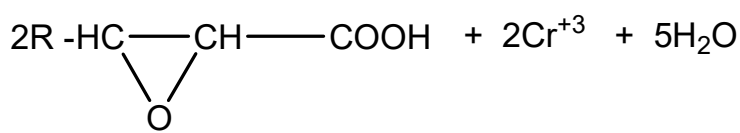

\section{Kinetic-Dependence}

Reactions showed first-order dependence on dichromate as presented in Fig.-1, but not depending upon starting concentrations of PDC. As the concentrations of acids are increased, the rate is also increasing but not in linear function as shown in Table-1. A graph between $1 / \mathrm{k}_{\text {Obs }}$ and $1 /$ [Acid] is intercepting on the rate axis, as shown in Fig.-2. Therefore, a fractional (less than one) kinetic picture is developed with respect to the reactant acids. This expression leads to postulate the reaction mechanism and the rate laws as given below represented as 2,3 and 4 respectively.

$$
\begin{aligned}
& \underset{\mathrm{k}_{2}}{\text { Unsaturated Acid }}+\mathrm{PDC} \underset{\mathrm{K}}{\mathrm{K}} \stackrel{\text { [complex }]}{\leftrightarrows} \\
& \text { Rate }=k_{2} \mathrm{~K}[\mathrm{USA}][\mathrm{PDC}] /(1+\mathrm{K}[\mathrm{USA}])
\end{aligned}
$$


RASĀYAN J. Chem.

Vol. 14 | No. 4 |2478-2485| October- December | 2021

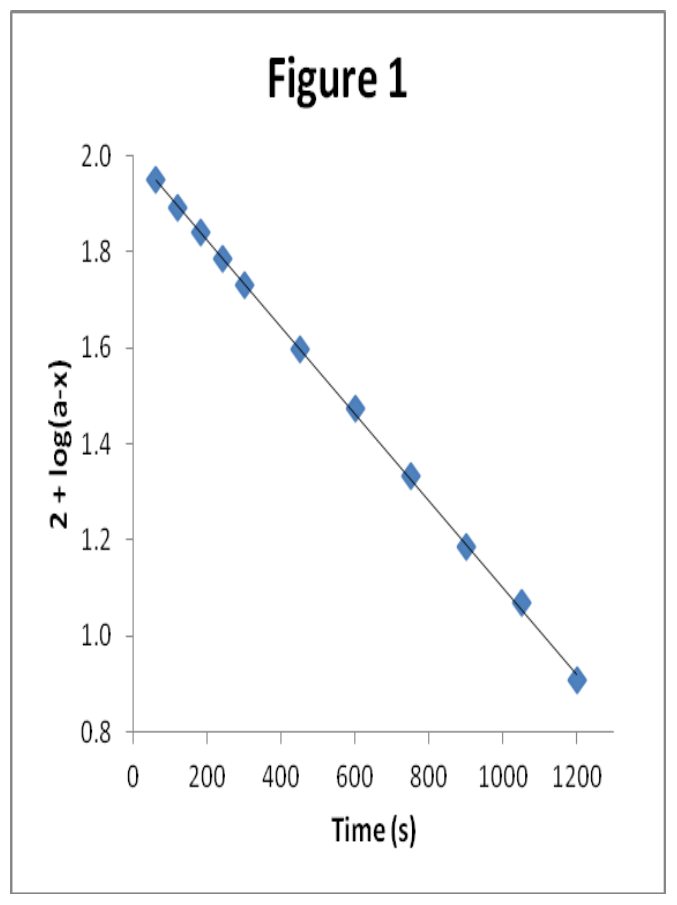

Fig.-1: Oxidation of Crotonic Acid by PDC: Linear sample graph

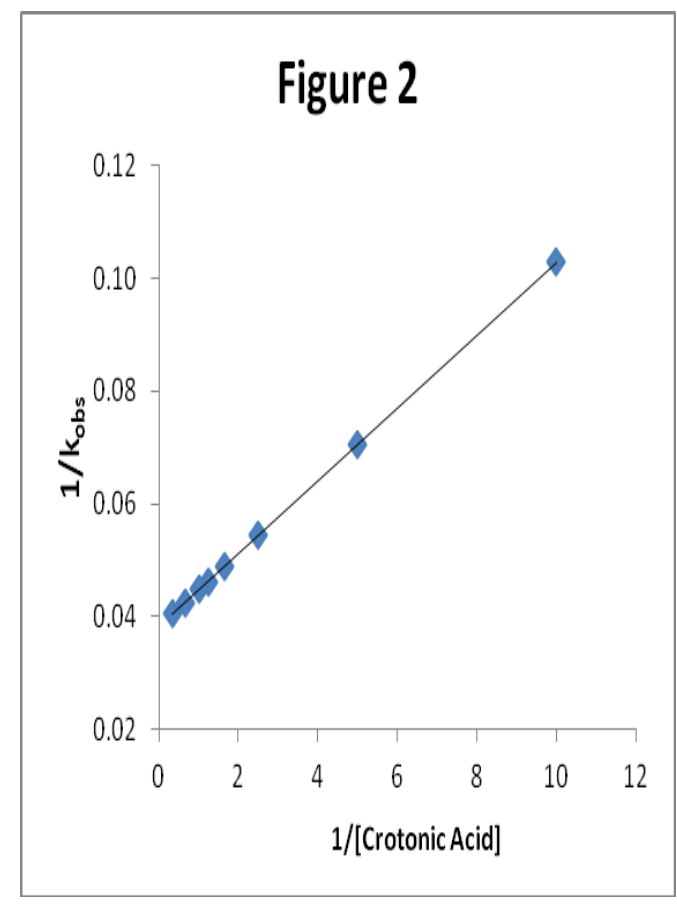

Fig.-2: Oxidation of Crotonic acid by PDC: Showing Intercept

Table-1: Oxidation of Crotonic Acid by PDC at $288 \mathrm{~K}$

\begin{tabular}{c|c|c|c}
\hline $10^{3}[\mathrm{PDC}]$ & {$[\mathrm{CrA}]$} & {$[\mathrm{TsOH}]$} & $10^{4} k_{\mathrm{obs}}$ \\
\hline$\left(\mathrm{mol} \mathrm{dm}^{-3}\right)$ & $\left(\mathrm{mol} \mathrm{dm}^{-3}\right)$ & $\left(\mathrm{mol} \mathrm{dm}^{-3}\right)$ & $\left(\mathrm{mol} \mathrm{dm}^{-3}\right)$ \\
\hline 1.0 & 0.10 & 0.00 & 6.37 \\
\hline 1.0 & 0.20 & 0.00 & 9.28 \\
\hline 1.0 & 0.40 & 0.00 & 12.0 \\
\hline 1.0 & 0.60 & 0.00 & 13.3 \\
\hline 1.0 & 0.80 & 0.00 & 14.1 \\
\hline 1.0 & 1.00 & 0.00 & 14.6 \\
\hline 1.0 & 1.50 & 0.00 & 15.4 \\
\hline 1.0 & 3.00 & 0.00 & 16.2 \\
\hline 2.0 & 0.40 & 0.00 & 12.6 \\
\hline 4.0 & 0.40 & 0.00 & 11.7 \\
\hline 6.0 & 0.40 & 0.00 & 12.3 \\
\hline 8.0 & 0.40 & 0.00 & 11.6 \\
\hline 1.0 & 0.20 & 0.00 & $9.54^{*}$ \\
\hline${ }^{\mathrm{a}}$ contained 0.001 M acrylonitrile & &
\end{tabular}

The rate of these reactions is dependent on [Acid], which is studied at four different temperatures. The data for formation constants and decomposition constant of the complex are calculated by graph number 2 , and the data of thermodynamic and activation parameters are also evaluated from $\mathrm{K}$ and $\mathrm{k} 2$ correspondingly, which are recorded in Tables- 2 and 3.

\section{Test For Free Radicals}

The oxidation of unsaturated acids, by PDC, in an atmosphere of nitrogen failed to induce the polymerization of acrylonitrile. Further, the addition of acrylonitrile had no effect on the rate (Table-1). We further confirm the absence of free radicals in the reaction pathway; the reaction was carried out in 
RASĀYAN J. Chem.

Vol. 14 | No. 4 |2478-2485| October-December | 2021

the presence of $0.05 \mathrm{~mol} \mathrm{dm}^{-3}$ of 2,6-di-t-butyl-4-methylphenol (butylated hydroxytoluene or BHT). It was observed that BHT was recovered unchanged, almost quantitatively.

Table-2: Rate constants for the decomposition of PDC-USA complexes and their activation parameters

\begin{tabular}{|c|c|c|c|c|c|c|c|}
\hline & \multicolumn{4}{|c|}{$10^{4} k_{2} /\left(\mathrm{dm}^{-3} \mathrm{~mol}^{-1} \mathrm{~s}^{-1}\right)$} & $\Delta H^{*}$ & $-\Delta S^{*}$ & $\Delta G^{*}$ \\
\hline USA & $288 \mathrm{~K}$ & $298 \mathrm{~K}$ & $308 \mathrm{~K}$ & $318 \mathrm{~K}$ & $\left(\mathrm{~kJ} \mathrm{~mol}^{-1}\right)$ & $\left.\mathrm{J} \mathrm{mol}^{-1} \mathrm{~K}^{-1}\right)$ & $\left(\mathrm{kJ} \mathrm{mol}^{-1}\right)$ \\
\hline FA & 4.41 & 7.56 & 12.6 & 20.7 & $36.7 \pm 0.1$ & $182 \pm 1$ & $90.8 \pm 0.1$ \\
\hline $\mathrm{CrA}$ & 17.1 & 19.7 & 52.2 & 89.1 & $39.5 \pm 0.5$ & $161 \pm 1$ & $87.4 \pm 0.4$ \\
\hline MA & 13.5 & 22.5 & 38.7 & 63.9 & $37.1 \pm 0.5$ & $172 \pm 2$ & $88.1 \pm 0.4$ \\
\hline $\mathrm{CiA}$ & 92.7 & 135 & 207 & 306 & $28.0 \pm 0.6$ & $187 \pm 2$ & $83.6 \pm 0.5$ \\
\hline
\end{tabular}

Table-3: Formation constants of decomposition of PDC-Acid complexes and thermodynamic parameters

\begin{tabular}{|c|c|c|c|c|c|c|c|}
\hline & \multicolumn{4}{|c|}{$\mathrm{K} /\left(\mathrm{dm}^{-3} \mathrm{~mol}^{-1} \mathrm{~s}^{-1}\right)$} & $\Delta H^{*}$ & $-\Delta S^{*}$ & $\Delta G^{*}$ \\
\hline USA & $288 \mathrm{~K}$ & $298 \mathrm{~K}$ & $308 \mathrm{~K}$ & $318 \mathrm{~K}$ & $\left(\mathrm{~kJ} \mathrm{~mol}^{-1}\right)$ & $\left.\mathrm{J} \mathrm{mol}^{-1} \mathrm{~K}^{-1}\right)$ & $\left(\mathrm{kJ} \mathrm{mol}^{-1}\right)$ \\
\hline FA & 6.30 & 5.51 & 4.68 & 3.90 & $14.7 \pm 0.5$ & $27 \pm 2$ & $6.68 \pm 0.4$ \\
\hline $\mathrm{CrA}$ & 5.94 & 5.15 & 4.35 & 3.51 & $15.7 \pm 0.8$ & $32 \pm 3$ & $6.51 \pm 0.6$ \\
\hline MA & 6.12 & 5.35 & 4.50 & 3.71 & $15.2 \pm 0.6$ & $29 \pm 2$ & $6.59 \pm 0.5$ \\
\hline $\mathrm{CiA}$ & 5.85 & 5.02 & 4.23 & 3.42 & $16.0 \pm 0.7$ & $33 \pm 2$ & $6.45 \pm 0.5$ \\
\hline
\end{tabular}

\section{Effect of Acidity}

As the medium is non-aqueous, para toluene sulfonic acids are used to study the effect of acid. This indicated that all the reactions have the catalysis effect of acid, which is represented by a common relation as given below. The data obtained for CrA for $a$ and $b$ are $6.60 \pm 0.38 \times 10^{-4} \mathrm{~s}^{-1}$ and $11.7 \pm 0.63 \times 10^{-4} \mathrm{dm}^{3}$ $\mathrm{mol}^{-1} \mathrm{~s}^{-1}\left(\mathrm{r}^{2}=0.9885\right)$.

$$
\mathrm{k}_{\mathrm{obs}}=\mathrm{a}+\mathrm{b}\left[\mathrm{H}^{+}\right]
$$

Table-4: Effect of Acidity on the rate of oxidation of CrA acid

\begin{tabular}{l|c|c|c|c|c|c}
\hline$[\mathrm{PDC}]=0.001 \mathrm{~mol} \mathrm{dm}^{-3} ;$ & [Crotonic acid] $=1.0 \mathrm{~mol} \mathrm{dm}{ }^{-3} ;$ & \multicolumn{4}{c}{ Temp. $=288 \mathrm{~K}$} \\
\hline$\left[\mathrm{H}^{+}\right] / \mathrm{mol} \mathrm{dm}^{-3}$ & 0.10 & 0.20 & 0.40 & 0.60 & 0.80 & 1.00 \\
\hline $\mathrm{CrA}$ & 7.92 & 9.18 & 11.0 & 13.5 & 15.3 & 18.9 \\
\hline
\end{tabular}

\section{Influence of Solvent Media}

We have studied the oxidation of fumeric acid / FA in a variety of 19 non-aqueous solvents. There is a limited choice of medium for the reaction of reagents and PDC with primary and secondary alcohol. No reaction was noticed with the medium taken to study. The kinetic nature of all the reactions is almost equal. The data for $\mathrm{k}$ and $\mathrm{k} 2$ are shown in Table- 5 given below.

Table-5: Effect of solvent on the rate of fumeric acid by PDC at $308 \mathrm{~K}$

\begin{tabular}{l|c|c|l|c|c}
\hline Solvents & $\begin{array}{c}\mathrm{K} \\
\left(\mathrm{dm}^{-3} \mathrm{~mol}^{-1}\right)\end{array}$ & $\begin{array}{c}10^{5} \mathrm{k}_{\text {obs }} \\
\left(\mathrm{s}^{-1}\right)\end{array}$ & Solvents & $\begin{array}{c}\mathrm{K} \\
\left(\mathrm{dm}^{-3} \mathrm{~mol}^{-1}\right)\end{array}$ & $\begin{array}{c}10^{5} \mathrm{k}_{\text {obs }} \\
\left(\mathrm{s}^{-1}\right)\end{array}$ \\
\hline $\mathrm{CHCl}_{3}$ & 6.12 & 33.9 & $\mathrm{C}_{6} \mathrm{H}_{5} \mathrm{CH}_{3}$ & 5.77 & 11.7 \\
\hline $1,2-\mathrm{C}_{2} \mathrm{H}_{4} \mathrm{Cl}_{2}$ & 5.88 & 39.8 & $\mathrm{C}_{6} \mathrm{H}_{5} \mathrm{COCH}_{3}$ & 6.00 & 45.7 \\
\hline $\mathrm{CH}_{2} \mathrm{Cl}_{2}$ & 5.85 & 44.7 & Tetrahydrofuran & 5.83 & 20.9 \\
\hline $\mathrm{DMSO}$ & 4.68 & 126 & t-Butylalcohol. & 5.52 & 14.1 \\
\hline $\mathrm{CH}_{3} \mathrm{COCH}$ & 6.03 & 39.8 & $1,4-\mathrm{C}_{4} \mathrm{H}_{8} \mathrm{O}_{2}$ & 5.60 & 18.2 \\
\hline Dimethyl formamide & 5.49 & 72.4 & $1,2-\mathrm{C}_{4} \mathrm{H}_{10} \mathrm{O}_{2}$ & 5.81 & 11.5 \\
\hline $\mathrm{C}_{4} \mathrm{H}_{8} \mathrm{O}$ & 5.85 & 26.3 & $\mathrm{Carbon} \mathrm{Disulphide}_{2}$ & 6.15 & 6.03 \\
\hline $\mathrm{Nitrobenzene}_{\mathrm{C}} \mathrm{H}_{6}$ & 5.63 & 51.3 & $\mathrm{CH}_{3} \mathrm{COOH}$ & 5.89 & 8.71 \\
\hline $\mathrm{C}_{6} \mathrm{H}_{12}$ & 6.12 & 14.8 & $\mathrm{C}_{2} \mathrm{H}_{5} \mathrm{COOC} \mathrm{C}_{2}$ & 6.11 & 13.2 \\
\hline
\end{tabular}


The rates constant, $\mathrm{k}_{2}$, in 18 different solvents $\left(\mathrm{CS}_{2}\right.$ is not taken into account because the full series of parameters is not present in literature) are to be correlated with the expression of Kamlet et al. ${ }^{16}$ LSER.

$$
\log k_{2}=\mathrm{A}_{0}+\mathrm{p} \pi^{*}+\mathrm{b} \beta+\mathrm{a} \alpha
$$

In the above expression :

$\pi^{*}$ is represented as the polarity of the solvents;

$\beta$ is represented as hydrogen bond acceptor basicity;

$\alpha$ is represented as hydrogen bond donor acidity.

And the $\mathrm{A}_{0}$ is to be the intercepted number.

It is to be noted that twelve solvents have the value of zero for alpha out of eighteen solvents. The results so obtained are given below (eqn.-8 to 11), which are calculated with bi-parametric expression given in eqn.-7.

$$
\begin{array}{ll}
\log \mathrm{k}_{2} & =-3.74+1.61( \pm 0.18) \pi^{*}+0.16( \pm 0.15) \beta+0.08( \pm 0.14) \alpha \\
\mathrm{R}^{2} & =0.8830 ; \quad \mathrm{sd}=0.16 ; \quad \mathrm{n}=18 ; \quad \psi=0.37 \\
\log \mathrm{k}_{2} & =-3.76+1.64( \pm 0.16) \pi^{*}+0.13( \pm 0.14) \beta \\
\mathrm{R}^{2} & =0.8799 ; \quad \mathrm{sd}=0.16 ; \quad \mathrm{n}=18 ; \quad \psi=0.37 \\
\log \mathrm{k}_{2}=-3.74+1.68( \pm 0.16) \pi^{*} & \\
\mathrm{r}^{2}=0.8726 ; \quad \mathrm{sd}=0.16 ; \quad \mathrm{n}=18 ; \quad \psi=0.37 \\
\log \mathrm{k}_{2}=-2.80+0.42( \pm 0.35) \beta \\
\mathrm{r}^{2}=0.0824 ; \quad \mathrm{sd}=0.42 ; \quad \mathrm{n}=18 ; \quad \psi=0.98
\end{array}
$$

In these equations, $\mathrm{n}$ is represented the number of data involved in the reaction and $\psi$ is Exner's mathematical parameter ${ }^{17}$.

This expression explains about $88 \%$ of data, but as per Exner's criterion ${ }^{17}$ this is not up to the satisfaction mark, equation 8 . The main role is played by solvent polarity, which explains about $87 \%$ of the data on its own. The role of $\beta$ and $\alpha$ is negligible.

Therefore, the solvent effect is also analyzed with Swain's equation ${ }^{18}$ expression of cation and anion solvating power conception of medium(eqn.-12).

$$
\log k_{2}=\mathrm{aA}+\mathrm{bB}+\mathrm{C}
$$

in this expression

A represented as anion solvating powers

$\mathrm{B}$ as cation solvating power.

$\mathrm{C}$ has represented the intercept term.

$(A+B)$ is treated as solvent polarity.

The data so obtained with the above expression is given below.

$$
\begin{aligned}
& \log \mathrm{k}_{2}=0.69( \pm 0.05) \mathrm{A}+1.65( \pm 0.03) \mathrm{B}-3.94 \\
& \mathrm{R}^{2}=0.9935 ; \mathrm{sd}=0.04 ; \mathrm{n}=19 ; \quad \psi=0.08 \\
& \log \mathrm{k}_{2}=0.45( \pm 0.55) \mathrm{A}-2.80 \\
& \mathrm{r}^{2}=0.0388 ; \mathrm{sd}=0.16 ; \mathrm{n}=19 ; \quad \psi=1.01 \\
& \log \mathrm{k}_{2}=1.60( \pm 0.13) \mathrm{B}-3.71 \\
& \mathrm{r}^{2}=0.9050 ; \mathrm{sd}=0.14 ; \mathrm{n}=19 ; \quad \psi=0.32 \\
& \log \mathrm{k}_{2}=1.33 \pm 0.13(\mathrm{~A}+\mathrm{B})-3.91 \\
& \mathrm{r}^{2}=0.8673 ; \mathrm{sd}=0.14 ; \mathrm{n}=19 ; \quad \psi=0.32
\end{aligned}
$$


Fumeric acid oxidation rates recorded in a variety of mediums show a very good relation with Swain expression model with the main role of cation solvating power on its explaining $90 \%$ of the results. A non-appreciable role of anion solvating powers is observed. The polarity of the solvent is also explaining $87 \%$ of the results; therefore the rate is correlated with the solvent relative permittivity. The graph between inverse relative permittivity and rate constant is non linear $\left(\mathrm{r}^{2}=0.5526 ; \mathrm{sd}=0.30 ; \psi=0.69\right)$.

\section{Mechanistic Aspects}

Our present study can be compared with chromyl chloride studies of alkenes, which has already taken extensive attention.

It is observed by the data obtained for activation enthalpy that breaking of bonds is not wide-spreading in the bond formation of the activated complex. The high negative value of entropy of activation indicated the presence of a cyclic activated firm complex. If we consider the activated complexes, the possible arrangements maybe I, II, III and IV. Structure III is similar to a 1-3-cycloaddition reaction which is specifically having the value zero ${ }^{19}$ as its reaction constant. Because of the high reaction constants values of reactions of substituted styrenes ${ }^{20}$ and alkenes ${ }^{21}(-1.99$ and -2.63$)$, structure III is doubtful.

It has been observed ${ }^{22-23}$ in the reactions having the involvement of high carbocationic in the complex, the reaction constant values are in the tune of -3 to -5 . Reddy and Sundaram ${ }^{24}$ reported the effect of electron attracting groups are having less and electron giving groups are having a considerable effect on reactivity in the oxidation of monosubstituted CiA by borate in acid media, where the value of reaction constant is 3.7 for electron attracting groups. Here the activated complex is supposed to be benzylic carbo cation in nature. It means the values so available about -2 , in the reactions of styrenes ${ }^{19} \mathrm{CrO}_{2} \mathrm{Cl}_{2}$ is nor favoring the complex with completely having positive charge i.e complex IV. In our reaction, the charge is increased to about moderately seven times by replacing a $-\mathrm{CH}_{3}$ group with $-\mathrm{C}_{6} \mathrm{H}_{5}$ group.

It is observed that maleic acid is oxidizing with a rate thrice higher than fumeric acid (three times), which is not in favor of complex II. Steric effects indicate that a four-member activated cyclic complex is more likely to take part in the reaction. The steric structure of Maleic acid, having 2 open ends is more prone to be attacked by PDC as compared to fumeric acid. If the four-membered structure is taking part, the difference in the rates of fumeric and maleic acid must be steeper. As per this idea, a three-membered structure is also weakly hampering the oxidation of Cis acid in comparison of trans acid. But by these results, one can not conclude that the activated structure II is taking part in the process. It has not been concluded by Freeman and co-workers ${ }^{11,20,21}$ also that which complex is taking part in the reaction process, three or four-membered.

Scrutiny of influence of solvent medium also in favor of the proposed mechanistic aspects. Actually, the present reaction is proceeding with much fast rate polar media because of 2 neutral molecules reacting to give moderately charge activated complexes. The main role of the cation solvating powers of the medium also supports the presence of an electron-less carbon center in the transition state. The low values of the regression coefficient, i.e., "b" are constant with the advancement of a little charge in the reactive complex. It may be confirmed by the fact that the value of " $b$ " is 1.73 in the case of benzaldehydes oxidation by $\mathrm{PFC}^{25}$ having a carbocationic reactive complex. With this long discussion, we are reaching the conclusion that both I and II may be the structures possibly taking part in the reaction as reactive complex, but structure I has more evidence in its favor.

At last, on the foundation of the investigative evidence and results, our proposal is in favor of the following Scheme-1 to be accepted for this reaction.

\section{CONCLUSION}

We are proposing this reaction proceeding through the considering the fact that of structure I of the unsaturated acids, because of observational evidence are in favor of structure I.

\section{ACKNOWLEDGEMENT}

Authors are thankful to UGC, New Delhi, for financial support in the form of UGC Basic Scientific Research Start-up grant to OP and to H.O.D. Chemistry, Jai Narain Vyas University, Jodhpur and PAHER University, Udaipur for laboratory facilities. 
RASĀYAN J. Chem.

Vol. 14 | No. 4 |2478-2485| October- December | 2021

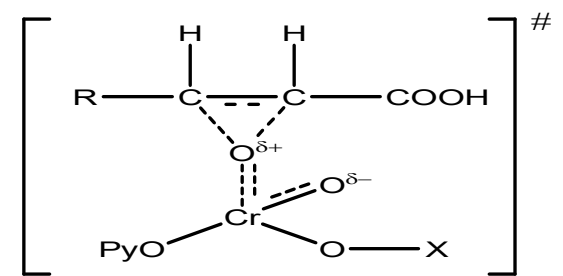

( I )

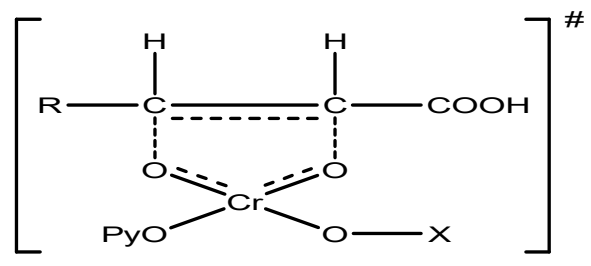

( III )

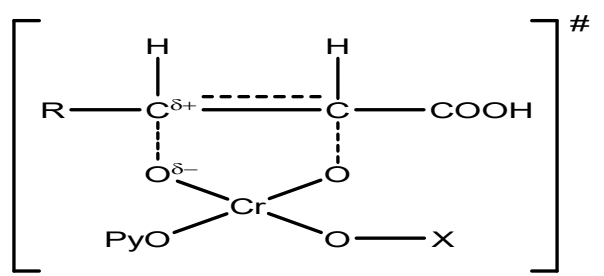

( II )

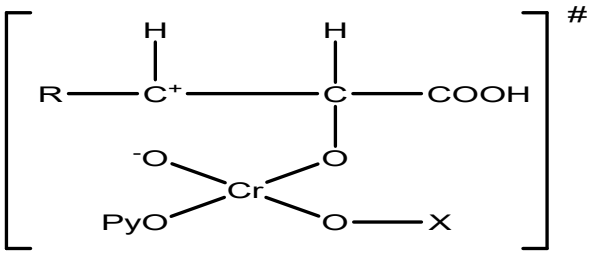

( IV)

[ $\left.\mathbf{x}=\mathrm{CrO}_{2} \mathrm{OPy}\right]$

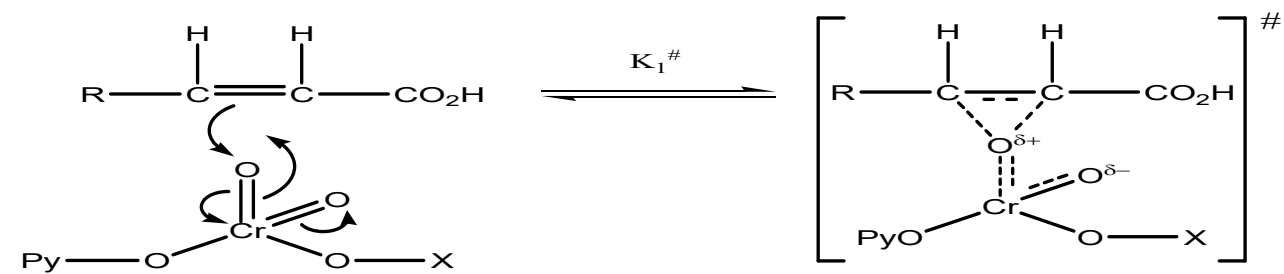<smiles>[X]O[Cl+2]([O-])O[Te]C</smiles>

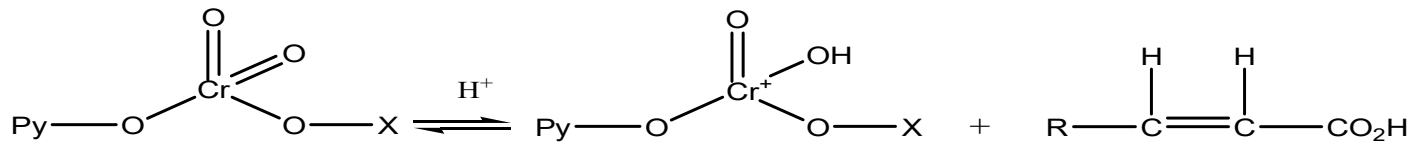<smiles></smiles><smiles>[Y][OH+][C-](O)O[Pb]</smiles>

Scheme-1

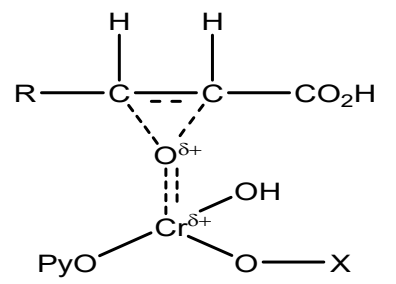

REFERENCES

1. G. Cainelli and G. Cardillo, Chromium Oxidations in Organic Chemistry, (Springer-Verlag, Berlin) Vol.19, (1984), https://doi.org/10.1007/978-3-642-69362-5 4

2. H. Firouzabadi and A. Sharifi, Synthesis, 10, 999(1992), https://doi.org/10.1055\%2Fs-1992-26288

3. M. $\mathrm{Li}$ and M.E. Johnson, Synthetic Communications, 25, 533(1995), https://doi.org/10.1080/00397919508011387 
RASĀYAN J. Chem.

Vol. 14 | No. 4 |2478-2485| October- December | 2021

4. M.K. Mahanti and K.K. Banerji, Journal of Indian Chemical Society, 79, 31(2002).

5. S. Kim and D. C. Lhim, Bulletin of Chemical Society of Japan, 59, 3297(1986),https://doi.org/10.1246/bcsj.59.3297

6. A. Choudhary, S. Agarwal and Vinita Sharma, Indian Journal of Chemistry, 48A, 362 (2009), http://nopr.niscair.res.in/handle/123456789/3373

7. A.K. Meena, A.Daiya, A. Sharma, J. Banerji, L. Kotai, and Vinita Sharma, Journal of Indian Chemical Society, 88(12), 1887(2011).

8. D. Sharma, P. Panchariya, K. Vadera and P.K. Sharma, Journal of Sulfur Chemistry, 32(4) 315(2011), https://doi.org/10.1080/17415993.2011.587519

9. A. Sharma, A. Meena J. Khatri, P. Swami and Vinita Sharma, Journal of Applicable Chemistry, 1(1) $70(2012)$.

10. T. Purohit, M. Patel, O. Praksh and P. K. Sharma, International Journal of Chemistry, 2(4) 436(2013).

11. F. Freeman and K.W. Arlcdge, Journal of Organic Chemistry, 37, 2656(1972).https://doi.org/10.1021/jo00982a004

12. A.K. Awasthy and J. Rocek, Journal of American Chemical Society, 91, 991(1969).https://doi.org/10.1021/ja01032a034

13. D. D. Perrin, W. L. Armarego, D. R. Perrin, Purification of Laboratory Chemicals, Pergamon Press, Oxford, 1966, https://doi.org/10.1002/recl.19881071209

14. K. B. Wiberg, P. Marshall and G. Foster, Tetrahedron Letters, 3(8),345(1962)https://doi.org/10.1016/S0040-4039(00)70878-1

15. R.T. Morrison and R.N. Boyd, Organic Chemistry, Prentice-Hall of India; New Delhi, 1989

16. M.J. Kamlet, J L M Abboud, M H Abraham, R W Taft, Journal of Organic Chemistry, 48, 2877 (1983), https://doi.org/10.1021/jo00165a018

17. O. Exner, Collection of Czechoslovak Chemical Communications, 31(8), 3222(1966), https://doi.org/10.1135/cccc19663222

18. C.G. Swain, S.H. Unger, N.R. Rosenquest and M.S. Swain, Journal of American Chemical Society, 105, 492(1983), https://doi.org/10.1021/ja00341a032

19. R. Huisgen, R. Grashey and J. Sauer, The Chemistry of Alkenes Ed. S. Patai, Interscience; London, 1964.

20. F. Freeman and N.J. Yamachika, Journal of American Chemical Society, 94, 1214(1972)and references cited therein, https://doi.org/10.1021/ja00759a031

21. F. Freeman, P.D. McCart and N.J. Yamachika, Journal of American Chemical Society, 92, 4621(1972), https://doi.org/10.1021/ja00718a026

22. J.R. Rolsten and K. Yates, Journal of American Chemical Society, 91, 1969(1969),https://doi.org/10.1021/ja01034a033

23. J.E. Dubois and A. Schawarcz, Tetrahedron Letters, 5(32), 2167(1964), https://doi.org/10.1016/S0040-4039(00)75149-5

24. C.S. Reddy and E.V. Sundaram, Tetrahedron, 45, 2109 (1989), https://doi.org/10.1016/S00404020(01)80072-7

25. S. Agarwal, K. Chowdhary and K.K. Banerji, Journal of Organic Chemistry, 56, 5111(1991), https://doi.org/10.1021/jo00017a023

[RJC-6557/2021] 